1. Riccardi, V.M. 1981. Cutaneous manifestation of neurofibromatosis: Cellular interaction, pigmentation, and mast cells. In Birth defects: original article series. Volume 17. R. Blandau, N. Paul, and F. Dickman, editors. Alan R. Lis Inc. New York, New York, USA. 129-145.

2. Yang, F.-C., et al. 2003. Neurofibromin-deficient Schwann cells secrete a potent migratory stimulus for $\mathrm{Nf}^{+/-}$mast cells. J. Clin. Invest. 112:1851-1861. doi:10.1172/JCI200319195.

3. Zhu, Y., Ghosh, P., Charnay, P., Burns, D.K., and Parada, L.F. 2002. Neurofibromas in NF1: Schwann cell origin and role of tumor environment. Science. 296:920-922.

4. Kluwe, L., Friedrich, R., and Mautner, V.F. 1999. Loss of NF1 allele in Schwann cells but not in fibroblasts derived from an NF1-associated neurofibroma. Genes Chromosomes Cancer. 24:283-285.

5. Serra, E., et al. 2000. Schwann cells harbor the somatic NF1 mutation in neurofibromas: evidence of two different Schwann cell subpopulations. Hum. Mol. Genet. 12:3055-3064.

6. Rutkowski, J.L., Wu, K., Gutmann, D.H., Boyer, P.J., and Legius, E. 2000. Genetic and cellular defects contributing to benign tumor formation in neurofibromatosis type 1 . Hum. Mol. Genet. 12:1059-1066.

7. Muir, D., Neubauer, D., Lim, I.T., Yachnis, A.T., and Wallace, M.R. 2001. Tumorigenic properties of neurofibromin-deficient neurofibroma Schwann cells. Am. J. Pathol. 158:501-513.
8. Fialkow, P.J., Sagebiel, R.W., Gartler, S.M., and Rimoin, D.L. 1971. Multiple cell origin of here ditary neurofibromas. N. Engl. J. Med. 284:298-300.

9. Greggio, H. 1911. Les cellules granuleuses (Mastzellen) dans les tissus normaux et dans certaines maladies chirurgicales. Arch. Med. Exp. 23:323-375

10. Gamble, H.J., and Goldby, S. 1961. Mast cells in peripheral nerve trunks. Nature. 189:766-767.

11. Olsson, Y. 1971. Mast cells in human peripheral nerve. Acta Neurol. Scand. 47:357-368.

12. Baroni, C. 1964. On the relationship of mast cells to various soft tissue tumours. $\mathrm{Br}$. J. Cancer. 18:686-690.

13. Pineda, A. 1965. Mast cells - their presence and ultrastructural characteristics in peripheral nerve tumors. Arch. Neurol. 13:372-382.

14. Isaacson, P. 1976. Mast cells in benign nerve sheath tumours. J. Pathol. 119:193-196.

15. Giorno, R., Lieber, J., and Claman, H.N. 1989. Ultrastructural evidence for mast cell activation in a case of neurofibromatosis. Neurofibromatosis. 2:35-41.

16. Carr, N.J., and Warren, A.Y. 1993. Mast cell numbers in melanocytic naevi and cutaneous neurofibromas. J. Clin. Pathol. 46:86-87.

17. Nurnberger, M., and Moll, I. 1994. Semiquantitative aspects of mast cells in normal skin and in neurofibromas of neurofibromatosis types 1 and 5. Dermatology. 188:296-299.

18. Hirota, S., et al. 1993. Possible involvement of c-kit receptor and its ligand in increase of mast cells in neurofibroma tissues. Arch. Pathol. Lab. Med. 117:996-999.

19. Bedache, A., Muja, N., and De Vries, G.H. 1998. Expression of Kit in neurofibromain-deficien human Schwann cells: role in Schwann cell hyperplasia associated with type 1 neurofibromatosis. Oncogene. 17:795-800.

20. Hannahan, D., and Weinberg, R.A. 2000. The hallmarks of cancer. Cell. 100:57-70.

21. Coussens, L.M., and Werb, Z. 2001. Inflammatory cells and cancer: think different. J. Exp. Med. 193:F23-F26.

22. Greenberg, G., and Burnstock, G. 1983. A novel cell-to-cell interaction between mast cells and other cell types. Exp. Cell. Res. 147:1-13.

23. Riccardi, V.M. 1987. Mast-cell stabilization to decrease neurofibroma growth. Arch. Dermatol. 123:1011-1016.

24. Riccardi, V.M. 1993. A controlled multiphase trial of ketotifen to minimize neurofibroma-associated pain and itching. Arch. Dermatol. 129:577-581.

25. Meyer, L.J. 1993. Drug therapy for neurofibromatosis? Arch. Dermatol. 129:625-626.

26. Coussens, L.M., and Werb, Z. 2002. Inflammation and cancer. Nature. 420:860-867.

27. Johnson, M.D., Kamso-Pratt, J., Federspiel, C.F. and Whetsell, W.O. 1989. Mast cell and lymphoreticular infiltrates in neurofibromas. Comparison with nerve sheath tumors. Arch. Pathol. Lab. Med. 113:1263-1270.

\title{
Tumbling down a different pathway to genetic instability
}

\section{Haiwei H. Guo and Lawrence A. Loeb \\ Joseph Gottstein Cancer Research Laboratory, Department of Pathology, University of Washington, Seattle, Washington, USA}

\begin{abstract}
Ulcerative colitis (UC), a chronic inflammatory condition associated with a predisposition to colon cancer, is frequently characterized by DNA damage in the form of microsatellite instability (MSI). A new report links inflammation in UC with increases in the DNA repair enzymes 3-methyladenine DNA glycosylase and apurinic/apyrimidinic endonuclease, and, paradoxically, with increased MSI (see the related article beginning on page 1887). These findings may represent a novel mechanism contributing to MSI in chronic inflammation.
\end{abstract}

J. Clin. Invest. 112:1793-1795 (2003). doi:10.1172/JCI200320502.

Address correspondence to: Lawrence A. Loeb, Department of Pathology, K-072 HSB, 1959 NE Pacific Street, University of Washington, Seattle, Washington 98195-7705, USA. Phone: (206) 543-6015; Fax: (206) 543-3967; E-mail: laloeb@u.washington.edu. Conflict of interest: The authors have declared that no conflict of interest exists. Nonstandard abbreviations used: ulcerative colitis (UC); chromosomal instability (CI); microsatellite instability (MSI); base excision repair (BER); 3-methyladenine DNA glycosylase (AAG); apurinic/apyrimidinic endonuclease (APE1); apurinic/apyrimidinic (AP); reactive oxygen species (ROS); polymerase $\beta$ (pol $\beta$ ).

\section{Ulcerative colitis, genetic instability, and cancer}

A longstanding question in cancer research is the strong association between certain chronic inflammatory conditions and the concomitant elevated risk for malignancy in affected tissues. Understanding the molecular mechanisms driving the progression to cancer may not only provide more effective means of prevention but also shed light on mechanisms of carcinogenesis. Ulcerative colitis (UC), which affects as many as 6 per 100,000 people in the
United States, is a relapsing form of chronic inflammatory disease of the large bowel. Patients with more than a 10-year history of disease have a 20- to 30 -fold greater risk of developing colorectal cancer (1). Both chromosomal instability (CI) and microsatellite (short, repetitive nucleotide sequences in DNA) instability (MSI) are present in UC and can be detected early in dysplastic, premalignant tissues $(2,3)$. What are the sources of these changes in DNA sequence? Chromosomal changes are frequent in cancer and MSI has been clearly documented as a result of mutations in mismatch repair enzymes in the hereditary nonpolyposis colon cancer syndrome. MSI is also observed in many other malignancies (4). Accumulation of mutations in microsatellites could be the result of alterations in enzymes that normally guarantee DNA stability, thus leading to a mutator phenotype (4). Existing hypotheses postulate that excess amounts of free radicals found in inflamed UC tissues overwhelm DNA repair pathways, leading to the accumulation of damaged DNA (5), or that mismatch repair pathways are inactivated, either directly by oxidative stress (6) or by hypermethylation (7). In the traditional view, members of DNA repair pathways are heroic players, stoically laboring against the overwhelming tide of genetic insults thrown their way. 


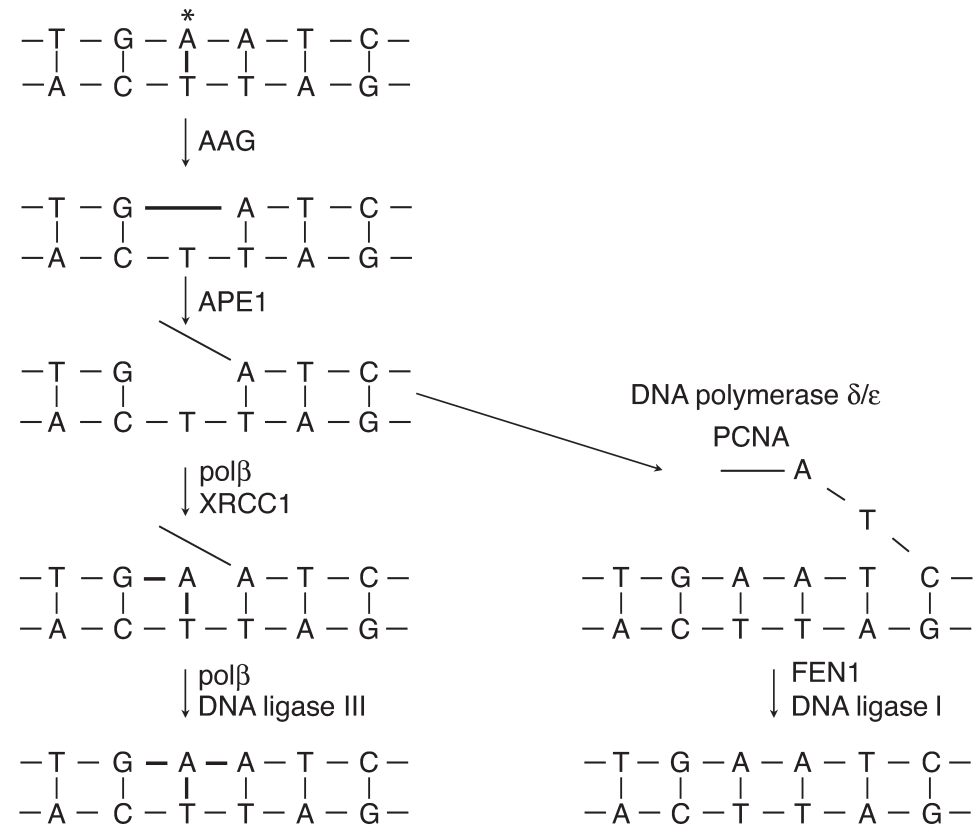

\section{DNA repair mechanisms: doing good and harm?}

A provocative hypothesis has now emerged, in which DNA repair enzymes are no longer seen as guardians of the genome but instead go awry, fumble like "Keystone Cops," and create unintended consequences in UC. The conceptual basis of this idea was introduced a decade ago, when Samson and Xiao first proposed and demonstrated that imbalanced base excision repair (BER) with broad substrate-specific 3-methyladenine DNA glycosylases could affect spontaneous mutation rates (8). While the mismatch repair pathway has frequently been the focus of MSI studies, in this issue of the JCI Hofseth and coworkers (9) instead considered the BER pathway, which includes the DNA repair enzymes 3-methyladenine DNA glycosylase (AAG) and apurinic/apyrimidinic endonuclease (APE1) (Figure 1) AAG removes a range of damaged bases, such as $N^{3}$-methyladenine $1, N^{6}$ ethenoadenine, and hypoxanthine from DNA by hydrolyzing the glyco-

\section{Figure 1}

Schematic illustrating base excision repair by a simple DNA glycosylase, AAG, which removes the damaged base but does not cleave the DNA backbone. APE1 makes a 5 nick in the backbone. In the short-patch pathway (left), pol $\beta$ synthesizes one nucleotide and removes the $5^{\prime}$-terminal baseless sugar via its lyase activity, supported by the scaffolding protein XRCC1. DNA ligase III seals the remaining nick. In the long-patch pathway (right), pol $\delta / \varepsilon$, supported by the replication factor PCNA, synthesizes a repair tract of two to six bases. FEN1 excises the overhanging flap, and DNA ligase I seals the remaining nick. Until the final ligation step is completed, toxic and mutagenic DNA repair intermediates, such as AP sites and single-stranded breaks, are still present in the genome. sylic bond attaching the damaged base to the deoxyribose sugar. APE1 processes the resulting apurinic/apyrimidinic (AP) site by incising the phosphodiester backbone of DNA immediately $5^{\prime}$ to the baseless sugar, leaving a strand break with a normal $3^{\prime}$ hydroxyl that can prime repair synthesis by DNA polymerases. APE1 can also process modified AP sites resulting from oxidative damage to deoxyribose. The authors theorize that the chronic inflammation in UC causes adaptive increases in AAG and APE1
Figure 2

Schematic illustrating the proposed mechanism of how chronic inflammation may induce microsatellite instability in ulcerative colitis. Among the factors released by inflammatory cells in ulcerative colitis are proinflammatory cytokines, ROS, and NO. Hofseth et al. (9) propose and provide evidence for inflammation-associated increases in the levels of the DNA repair enzymes AAG and APE1, which in turn produce instability at microsatellite sequences in various types of cells in the affected tissue (shown here as a colonic crypt stem cell). The exact mechanism through which AAG and APE1 produce MSI remains to be elucidated, but it may be related to imbalances in the components of the base excision repair pathway and the accumulation of mutagenic repair intermediates.

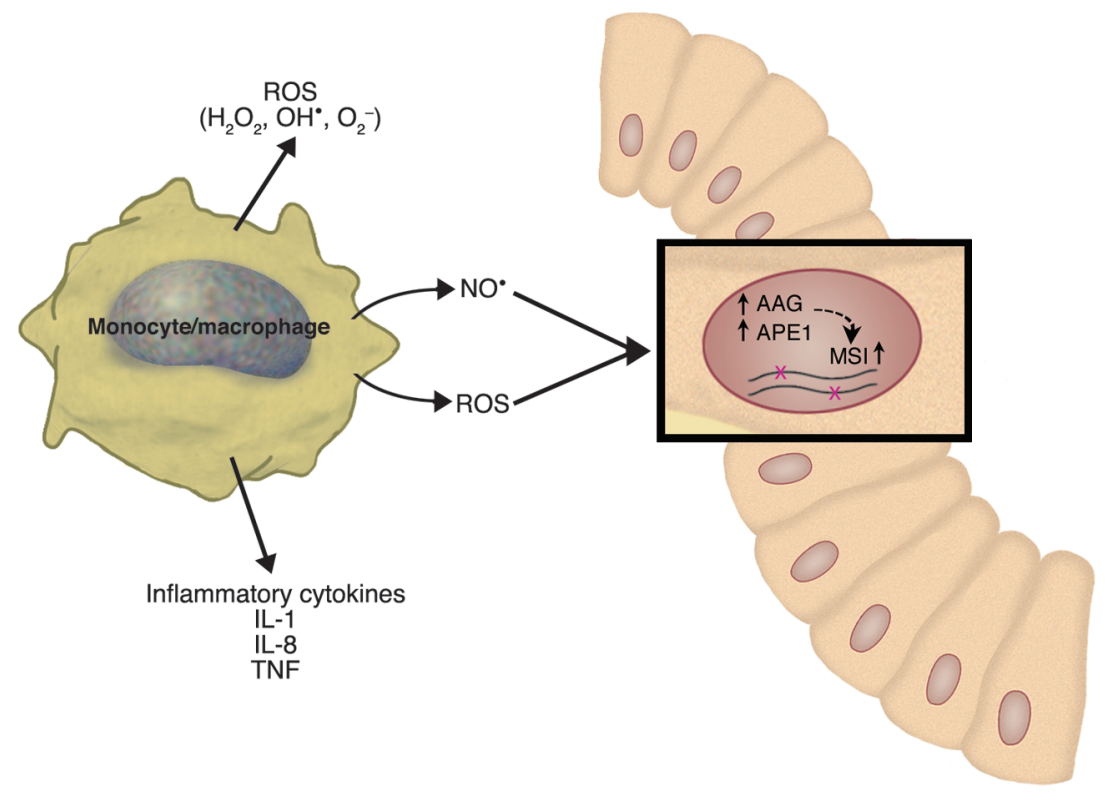


levels, which paradoxically enhance MSI in affected tissues, suggesting that these enzymes, which normally facilitate DNA repair, are instead causing mutations.

The authors proceeded by showing that there are significantly greater amounts of AAG and APE1 proteins in active inflamed areas of UC lesions than in noninflamed areas from the same patient; and that AAG and APE1 enzymatic activities are positively correlated with increased inflammation, as measured by the level of CD68, a monocyte and macrophage marker (Figure 2) (9). Furthermore, AAG and APE1 activities were positively correlated with the degree of MSI instability of the UC colon tissue. However, guilt by statistically significant association should not persuade a competent jury of causality. So the authors provide more definitive evidence. Overexpression of AAG alone or in addition to APE1 in mismatch repair-proficient yeast produced increases of as much as 30 -fold in -1 and 6 -fold in +1 frameshift mutations. Furthermore, co-overexpression of AAG and APE1 in the human erythroleukemic cell line K562 produced instability at four of seven microsatellite loci examined, whereas no MSI was detected in the vector-only control. Together, these results suggest that adaptive increases in the BER enzymes AAG and APE1 contribute to MSI in UC.

\section{More questions}

The work of Hofseth et al. (9) raises new questions. Given that reactive oxygen species (ROS) are known to activate APE1 in human cells $(10,11)$, what signaling pathways are involved in the pathway from chronic inflammation to AAG and APE1 induction? Are other BER pathway enzymes, such as DNA glycosylases that repair oxidative damage, the downstream DNA polymerase $\beta$ (pol $\beta$ ), and ligases also imbalanced and do they also contribute to MSI in UC? Recently it was shown that pol $\beta$ overexpression leads to low levels of MSI in cultured cells (12). Given that many UC lesions exhibit $\mathrm{CI}$, are increased AAG and
APE1 activities also associated with other types of mutations? Are there greater frequencies of double-stranded DNA breaks generated by APE1-mediated cleavage at closely opposed lesions? What is the mechanism by which AAG and APE1 produce MSI? Because of the many enzymes involved in the complex chemistry of recognizing and removing DNA lesions, resynthesizing DNA, and ligating the nicked strands to restore the original DNA content, and because many repair intermediates, such as AP sites and single-strand breaks, are themselves mutagenic and cytotoxic (13), it is intuitive that the BER pathway requires tight coordination to efficiently and safely process lesions (14). Dysregulation of components of the BER pathway can result in mutagenesis $(8,15)$. Interestingly, other DNA repair pathways, such as mismatch repair and nucleotide excision repair, also face these same challenges. Therefore, do mutations also result from dysregulation of these other pathways?

More broadly, many polymorphisms exist in DNA repair genes $(16,17)$, and many of these are likely to have functional consequences. If imbalances in DNA repair pathways lead to genetic instability, then are individuals with certain alleles or combinations of alleles more prone to genetic instability? The study by Hofseth et al. (9) encourages examination of BER pathways as agents of MSI in other chronic inflammatory diseases with a proclivity to cancer, such as chronic hepatitis and chronic pancreatitis. Many sporadic tumors also display MSI, including cancers of the endometrium, breast, lung, stomach, ovary, prostate, esophagus, bladder, glia, cervix, and pancreas. Evidence of mutations in mismatch repair in many of these cancers is lacking (18). Could a mechanism similar to the one described here by Hofseth et al. (9) also be associated with MSI in some of these tumors? One of life's aphorisms is that there are many ways to scramble an egg. Hofseth et al. focused on a small part of the vast proteomic changes induced by inflammation. Their work highlights the idea that in the future we may discover even more ways that cells can tumble down the path toward genetic instability.

1. Ekbom, A., Helmick, C., Zack, M., and Adami, H.O. 1990. Ulcerative colitis and colorectal cancer. A population-based study. N. Engl. J. Med. 323:1228-1233

2. Willenbucher, R.F., et al. 1999. Genomic instability is an early event during the progression pathway of ulcerative-colitis-related neoplasia. Am.J. Pathol. 154:1825-1830.

3. Rubin, C.E., et al. 1992. DNA aneuploidy in colonic biopsies predicts future development of dysplasia in ulcerative colitis. Gastroenterology. 103:1611-1620

4. Loeb, L.A., Loeb, K.R., and Anderson, J.P. 2003 Multiple mutations and cancer. Proc. Natl. Acad. Sci. U. S. A. 100:776-781.

5. Loeb, K.R., and Loeb, L.A. 1999. Genetic instability and the mutator phenotype. Studies in ulcerative colitis. Am. J. Pathol. 154:1621-1626.

6. Chang, C.L., et al. 2002. Oxidative stress inactivates the human DNA mismatch repair system. Am. J. Physiol. Cell Physiol. 283:C148-C154.

7. Fleisher, A.S., et al. 2001. Hypermethylation of the hMLH1 gene promoter is associated with microsatellite instability in early human gastric neoplasia. Oncogene. 20:329-335.

8. Xiao, W., and Samson, L. 1993. In vivo evidence for endogenous DNA alkylation damage as a source of spontaneous mutation in eukaryotic cells. Proc. Natl. Acad. Sci. U. S. A. 90:2117-2121.

9. Hofseth, L.J., et al. 2003. The adaptive imbalance in base excision-repair enzymes generates microsatellite instability in chronic inflammation. J. Clin. Invest. 112:1887-1894. doi:10.1172/JCI200319757.

10. Ramana, C.V., Boldogh, I., Izumi, T., and Mitra, S 1998. Activation of apurinic/apyrimidinic endonuclease in human cells by reactive oxygen species and its correlation with their adaptive response to genotoxicity of free radicals. Proc. Natl. Acad. Sci. U. S. A. 95:5061-5066.

11. Silber, J.R., et al. 2002. The apurinic/apyrimidinic endonuclease activity of Ape1/Ref- 1 contributes to human glioma cell resistance to alkylating agents and is elevated by oxidative stress. Clin. Cancer Res. 8:3008-3018.

12. Yamada, N.A., and Farber, R.A. 2002. Induction of a low level of microsatellite instability by overexpression of DNA polymerase Beta. Cancer Res. 62:6061-6064.

13. Sobol, R.W., et al. 2003. Base excision repair intermediates induce p53-independent cytotoxic and genotoxic responses. J. Biol. Chem. 278:39951-39959.

14. Wilson, S.H., and Kunkel, T.A. 2000. Passing the baton in base excision repair. Nat. Struct. Biol. 7:176-178

15. Glassner, B.J., Rasmussen, L.J., Najarian, M.T., Posnick, L.M., and Samson, L.D. 1998. Generation of a strong mutator phenotype in yeast by imbalanced base excision repair. Proc. Natl. Acad. Sci. U. S. A. 95:9997-10002.

16. de Boer, J.G. 2002. Polymorphisms in DNA repair and environmental interactions. Mutat. Res 509:201-210.

17. Goode, E.L., Ulrich, C.M., and Potter, J.D. 2002. Polymorphisms in DNA repair genes and associations with cancer risk. Cancer Epidemiol. Biomarkers Prev. 11:1513-1530

18. Jackson, A.L., and Loeb, L.A. 1998. The mutation rate and cancer. Genetics. 148:1483-1490. 